\title{
Effect of influenza vaccination in patients with asthma
}

\author{
Iván Martínez-Baz PhD, Ana Navascués MD, Itziar Casado MD PhD, María Eugenia Portillo PhD, \\ Marcela Guevara MD PhD, Carlos Gómez-lbáñez MD, Cristina Burgui PharmD, Carmen Ezpeleta MD PhD, \\ Jesús Castilla MD PhD
}

Cite as: CMAJ 2021 July 26;193:E1120-8. doi: 10.1503/cmaj.201757

\begin{abstract}
BACKGROUND: Although annual influenza vaccination is recommended for persons with asthma, its effectiveness in this patient population is not well described. We evaluated the effect of influenza vaccination in the current and previous seasons in preventing influenza among people with asthma.
\end{abstract}

METHODS: Using population health data from the Navarre region of Spain for the 2015/16 to 2019/20 influenza seasons, we conducted a test-negative case-control study to assess the effect of influenza vaccination in the current and 5 previous seasons. From patients presenting to hospitals and primary health care centres with influenza-like illness who underwent testing for influenza, we estimated the effects of influenza vaccination among patients with asthma overall and between those presenting as inpatients or outpatients, as well as between patients with and without asthma.

RESULTS: Of 1032 patients who had asthma and were tested, we confirmed that 421 had influenza and the remaining 611 were test-negative controls. We found that the average effect of influenza vaccination was $43 \%$ (adjusted odds ratio [OR] $0.57,95 \%$ confidence interval $[\mathrm{Cl}] 0.40$ to 0.80 ) for currentseason vaccination regardless of previous doses, and 38\% (adjusted OR 0.62,
$95 \% \mathrm{Cl} 0.39$ to 0.96 ) for vaccination in previous seasons only. Effects were similar for outpatients and inpatients. Among patients with asthma and confirmed influenza, current-season vaccination did not reduce the odds of hospital admission (adjusted OR 1.05, $95 \% \mathrm{Cl} 0.51$ to 2.18 ). Influenza vaccination effects were similar for patients with and without asthma.

INTERPRETATION: We estimated that, on average, current or previous influenza vaccination of people with asthma prevented almost half of influenza cases. These results support recommendations that people with asthma receive influenza vaccination. nfluenza can lead to serious complications in people with risk factors, and the main preventive measure is vaccination. ${ }^{1}$ Influenza infection can exacerbate symptoms of asthma. Because people with asthma have an increased risk of severe complications and hospital admission when infected with influenza virus,,$^{2-5}$ annual influenza vaccination is recommended worldwide for people with asthma. ${ }^{1,5-8}$

People who are targeted for influenza vaccination frequently accumulate several doses over successive years, ${ }^{9}$ and adherence to influenza vaccination has been found to be higher in those with asthma. ${ }^{10}$ Patients with asthma frequently receive long-term corticosteroid treatment (inhaled or oral), therefore, their systemic immunity may have a reduced response to vaccines. ${ }^{5,11,12}$

Effectiveness of influenza vaccines in preventing primary health care consultations or hospital admissions in people with asthma has been evaluated in observational studies, ${ }^{13-15}$ but we are unaware of any studies that compared the effect in preventing outpatient and inpatient cases or assessed the effect of vaccination in previous seasons. ${ }^{13,16}$ The test-negative design is the suggested method to evaluate effectiveness of influenza vaccines in preventing laboratory-confirmed influenza, because it achieves good comparability and control of bias. ${ }^{17-19}$ Only 1 study used this method for people with asthma over several seasons. ${ }^{13}$ The pooled analysis of several seasons, the inclusion of inpatients and outpatients, and consideration of vaccination history would provide a complete view of the effect of influenza vaccination in people with asthma.

Our objective was to assess the average effect of influenza vaccination status in the current and previous seasons on preventing laboratory-confirmed influenza among people with asthma. We also aimed to compare these estimates with those of the target population for influenza vaccination. 


\section{Methods}

\section{Study population and data}

This study was undertaken in the region of Navarre (about 650000 inhabitants), Spain, where annual studies of the effectiveness of influenza vaccines have been conducted since 2009. ${ }^{20-22}$ The Navarre Health Service provides health care to residents free at the point of use. The trivalent inactivated influenza vaccine was offered annually free of charge to the target population, which included people older than 6 months with conditions that increased risk for severe illness, including asthma, and all those aged 60 years or older. Each dose of vaccine was recorded at the time of administration. ${ }^{9}$

We based our influenza surveillance on electronic reporting of cases of medically attended influenza-like illness from all primary health care centres and hospitals in the region. Protocols indicated detection and swabbing of all cases with influenza-like illness in hospitals and by sentinel general practitioners. ${ }^{20}$ We defined influenza-like illness as the sudden onset of any general flu-like symptom (e.g., fever or feverishness, malaise, headache or myalgia) in addition to any respiratory symptom (e.g., cough, sore throat or shortness of breath). ${ }^{23}$ Swabs of patients were tested for influenza virus by real-time reverse-transcription polymerase chain reaction (RT-PCR) and results were entered in electronic laboratory records.

In every influenza vaccination campaign, we obtained information on previous diagnoses of asthma and other major chronic conditions (i.e., cardiovascular disease, diabetes, chronic obstructive pulmonary disease, renal disease, cancer, liver cirrhosis, dementia, stroke, immunodeficiency, rheumatic disease and body mass index of $40 \mathrm{~kg} / \mathrm{m}^{2}$ or more) from electronic medical records. These conditions were coded according to the International Classification of Primary Care, 2nd edition, and patients with asthma were identified using the code R96. ${ }^{24}$

We obtained influenza vaccination status for each patient in the current and 5 previous seasons from the electronic regional vaccination register. ${ }^{9}$ We used a unique identification number to link patient information.

\section{Study design and outcomes}

We evaluated the average effect over 5 seasons (2015/16 to 2019/20) of the influenza vaccination status in the current and previous seasons. We conducted a test-negative case-control study nested in the cohort of the population covered by the Navarre Health Service and included patients with residence in the region during the 5 years before the analyzed influenza season. We included patients who were in hospital or seen in primary health care centres for influenza-like illness and were tested for influenza virus using RT-PCR. We were blinded to vaccination status and test results for patients during the inclusion process. We excluded children younger than 9 years, health care workers and residents of nursing homes because they use health services differently. Cases were patients with asthma who were confirmed for influenza virus, and controls were similar patients who tested negative for influenza virus (Figure 1A). We performed separate analyses for inpatients and outpatients, and we evaluated the effect of influenza vaccination on the odds of hospital admission for influenza in a case-to-case comparison (Figure 1B). ${ }^{25}$ Finally, we used a testnegative case-control design to analyze the target population for influenza vaccination to compare the effect of influenza vaccination between persons with and without asthma (Figure 1C).

\section{Statistical analysis}

We used the $\chi^{2}$ test to compare the characteristics of cases and controls. We used logistic regression to calculate crude and adjusted odds ratios (ORs) with 95\% confidence intervals (Cls). Adjustment variables were age group, major chronic conditions, health care setting (primary health care or hospital), and month and season of sample collection. We estimated the influenza vaccination effect as $(1-$ OR $) \times 100$.

We evaluated the effect of influenza vaccination from the point of view of the population to inform about the overall benefit expected for combinations of influenza vaccination status in the current and previous seasons. When differences among category estimates were not statistically significant, to simplify the presentation of results, we aggregated these categories as follows: current-season vaccination (regardless of previous doses), vaccination in previous seasons only and neither current-season vaccination nor previous doses as the reference category. ${ }^{26}$

We analyzed the interaction terms between vaccination status and covariables. We conducted stratified analyses by age group, presence of other major chronic conditions, influenza season, health care setting and virus subtype. For each influenza subtype analysis, we included seasons with a minimum number of cases only.

We used logistic regression to estimate adjusted ORs for influenza in people with asthma compared to those without asthma who had a similar influenza vaccination status.

\section{Ethics approval}

The Navarre Ethical Committee for Medical Research approved the study protocol. Analyses were performed with anonymized data.

\section{Results}

During the 5 influenza seasons, swabs were taken from 1032 patients with asthma who had influenza-like illness; 741 (71.8\%) were admitted to hospital and 291 (28.2\%) were seen in primary health care. Influenza was confirmed in 421 (40.8\%) patients: 155 with $\mathrm{A} / \mathrm{H} 1 \mathrm{~N} 1,149$ with $\mathrm{A} / \mathrm{H} 3 \mathrm{~N} 2,114$ with influenza $B, 1$ with influenza $A$ and $B$ coinfection, and 2 with influenza $A$ that were not subtyped. There were 611 patients with negative test results for influenza (Figure $1 A$ ).

Characteristics of patients with and without influenza (controls) are described in Table 1 and Appendix 1, Supplementary Table A1, available at www.cmaj.ca/lookup/doi /10.1503/cmaj.201757/tab-related-content.

\section{Influenza vaccination effect in patients with asthma}

Among patients with asthma who were confirmed to have influenza, $42.5 \%$ had received the current-season vaccine and another $12.6 \%$ were not currently vaccinated but had received a dose in previous seasons. Among patients with asthma in whom 
A



B

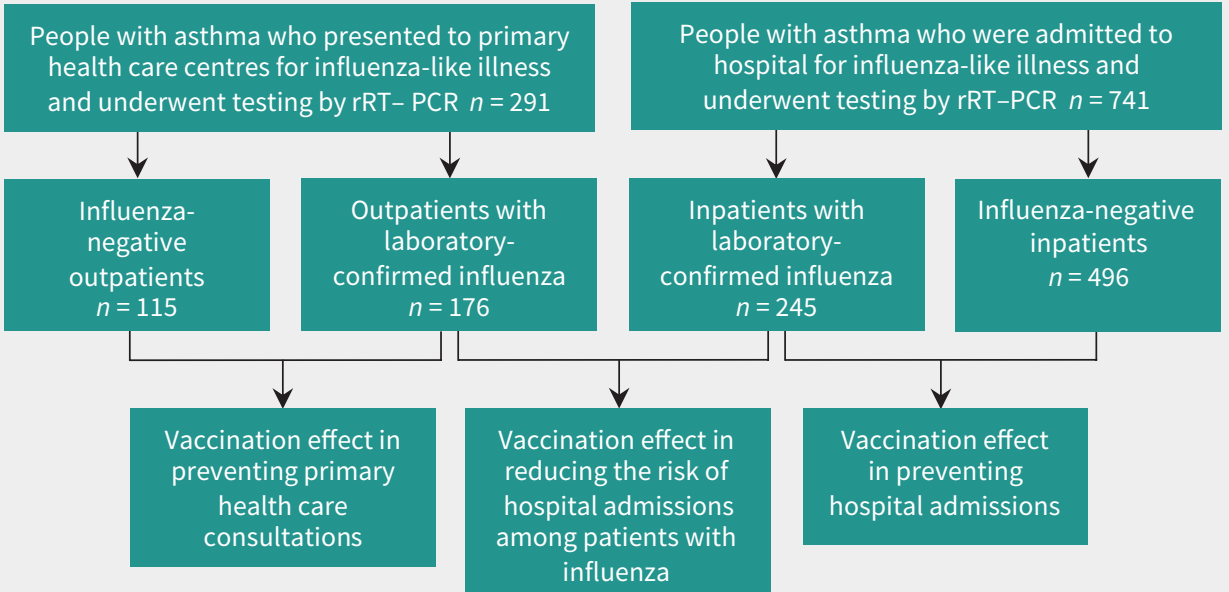

C

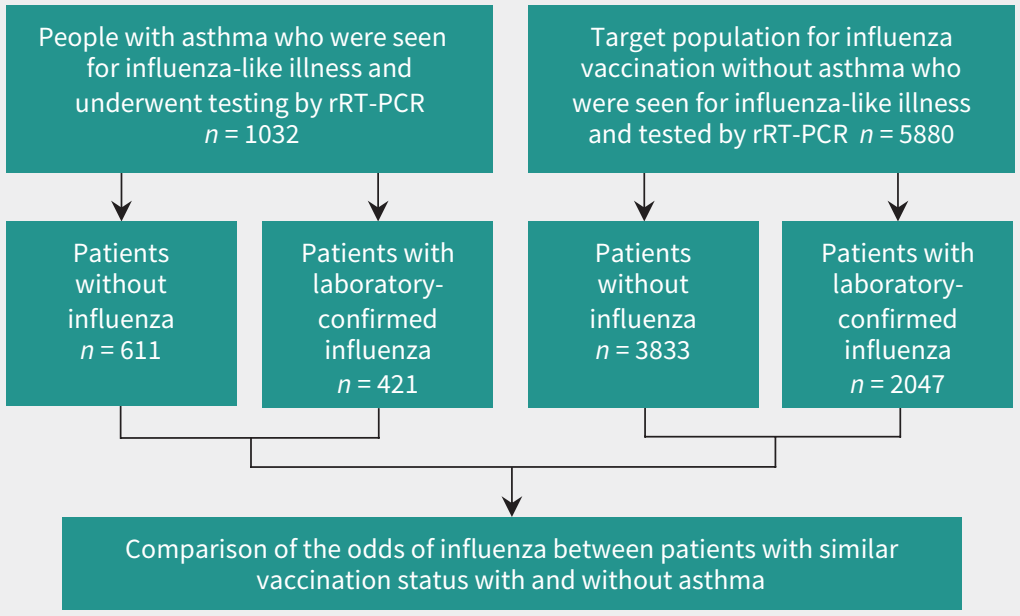

Figure 1: Flow charts for the study groups and comparisons made. (A) Overall analyses in patients with asthma. (B) Analyses by health care setting. (C) Comparison of patients with and without asthma. Note: rRT-PCR = real-time reverse-transcription-polymerase chain reaction.

influenza was excluded, $57.8 \%$ had received the current-season vaccine and $16.7 \%$ had received a dose in previous seasons. The overall protective effect against influenza was 43\% (OR 0.57, 95\% $\mathrm{Cl} 0.40$ to 0.80 ) in patients who were vaccinated in the current season regardless of vaccination in previous seasons, and $38 \%$ (OR $0.62,95 \% \mathrm{Cl} 0.39$ to 0.96 ) in patients who were vaccinated in previous seasons but not the current one, compared with those with asthma who were not vaccinated in the current and 5 previous seasons (Table 2 and Figure 2).

We found that the estimated influenza vaccination effect for current-season vaccination was similar in outpatients and inpatients (44\%, OR $0.56,95 \% \mathrm{Cl} 0.29$ to 1.07 v. $46 \%$, OR $0.54,95 \% \mathrm{Cl} 0.35$ 
Table 1: Characteristics of patients with asthma presenting with influenza-like illness, by influenza infection status

\begin{tabular}{|c|c|c|c|}
\hline Characteristic & $\begin{array}{l}\text { No. }(\%) \text { of } \\
\text { patients } \\
\text { with } \\
\text { confirmed } \\
\text { influenza } \\
n=421\end{array}$ & $\begin{array}{c}\text { No. }(\%) \text { of } \\
\text { influenza- } \\
\text { negative } \\
\text { patients } \\
n=611\end{array}$ & $p$ value \\
\hline Age group, yr & & & $<0.001$ \\
\hline $9-64$ & $240(57.0)$ & $239(39.1)$ & \\
\hline $65-84$ & $126(29.9)$ & $271(44.4)$ & \\
\hline$\geq 85$ & $55(13.1)$ & $101(16.5)$ & \\
\hline Sex & & & 0.2 \\
\hline Male & $181(43.0)$ & $237(38.8)$ & \\
\hline Female & $240(57.0)$ & $374(61.2)$ & \\
\hline Health care setting & & & $<0.001$ \\
\hline Primary health care & $176(41.8)$ & $115(18.8)$ & \\
\hline Hospital & $245(58.2)$ & $496(81.2)$ & \\
\hline \multicolumn{4}{|c|}{ Other major chronic conditions } \\
\hline Diabetes & $53(15.0)$ & $145(23.7)$ & 0.001 \\
\hline Cancer & $57(13.5)$ & $131(21.4)$ & 0.001 \\
\hline Liver cirrhosis & $14(3.3)$ & $33(5.4)$ & 0.1 \\
\hline Renal disease & 49 (11.6) & $99(16.2)$ & 0.04 \\
\hline Immunodeficiency & $8(1.9)$ & $7(1.1)$ & 0.3 \\
\hline $\begin{array}{l}\text { Chronic obstructive } \\
\text { pulmonary disease }\end{array}$ & $53(12.6)$ & $91(14.9)$ & 0.3 \\
\hline Cardiovascular disease & $85(20.2)$ & $185(30.3)$ & $<0.001$ \\
\hline Dementia & $8(1.9)$ & $17(2.8)$ & 0.4 \\
\hline Stroke & $10(2.4)$ & $34(5.6)$ & 0.01 \\
\hline Rheumatic disease & $6(1.4)$ & $18(2.9)$ & 0.1 \\
\hline $\begin{array}{l}\text { Body mass index } \\
\geq 40 \mathrm{~kg} / \mathrm{m}^{2}\end{array}$ & $20(4.8)$ & $42(6.9)$ & 0.2 \\
\hline $\begin{array}{l}\text { Influenza vaccination } \\
\text { status in the current and } \\
5 \text { previous seasons }\end{array}$ & & & $<0.001$ \\
\hline Never vaccinated & $189(44.9)$ & $156(25.5)$ & \\
\hline $\begin{array}{l}\text { Vaccination in previous } \\
\text { seasons only }\end{array}$ & $53(12.6)$ & $102(16.7)$ & \\
\hline $\begin{array}{l}\text { Current-season } \\
\text { vaccination }\end{array}$ & $179(42.5)$ & $353(57.8)$ & \\
\hline Influenza season & & & $<0.001$ \\
\hline $2015 / 16$ & $81(19.2)$ & $71(11.6)$ & \\
\hline $2016 / 17$ & $52(12.4)$ & $94(15.4)$ & \\
\hline $2017 / 18$ & $126(29.9)$ & $146(23.9)$ & \\
\hline $2018 / 19$ & $89(21.1)$ & $153(25.0)$ & \\
\hline $2019 / 20$ & $73(17.3)$ & $147(24.1)$ & \\
\hline
\end{tabular}

Note: Current-season vaccination = vaccinated in the current season regardless of previous doses. to $0.84 ; p=1.0$ for the interaction) (Figures $1 \mathrm{~B}$ and 2 , and Appendix 1 , Supplementary Tables A2 and A3). Vaccination in previous seasons was associated with numerically greater protection against hospital admissions than with outpatient cases of influenza, but the difference was not statistically significant $(42 \%$, OR $0.58,95 \% \mathrm{Cl} 0.40$ to 0.80 v. $23 \%, \mathrm{OR} 0.77,95 \% \mathrm{Cl} 0.29$ to $1.03 ; p=0.7$ for the interaction).

We found that effects of vaccination in the current season (with or without vaccination in previous seasons) and vaccination only in previous seasons did not differ significantly between patients with or without other major chronic conditions $(p=0.4$ and $p=0.09$ for the interaction, respectively) (Figure 2), or between patients aged 9-64 years and patients aged 65 years or older ( $p=0.3$ and $p=0.9$ for the interaction, respectively), and were also similar among different influenza virus subtypes (Table 3). Estimates of influenza vaccination effect showed high variability among influenza seasons, with effects related to current-season vaccination ranging between $8 \%$ and $64 \%$ (Appendix 1, Supplementary Table A4).

Among asthma patients confirmed to have influenza (Figure 1C), influenza vaccination was not associated with a significant reduction in hospital admissions compared with outpatient presentation, either for current-season vaccination (OR $1.05,95 \% \mathrm{Cl} 0.51$ to 2.18 ) or for vaccination in previous seasons only (OR 2.11, 95\% $\mathrm{Cl} 0.88$ to 5.07) (Table 4).

\section{Vaccination effect in persons with and without asthma}

A total of 6912 patients with major chronic conditions or aged 60 years or older presented to primary care centres or were admitted to hospital with influenza-like illness and underwent testing for influenza during the study periods. We compared the odds of being confirmed to have influenza between 1032 (14.9\%) patients with asthma and $5880(85.1 \%)$ patients without asthma who had similar influenza vaccination status. The odds of having influenza between people with and without asthma did not differ significantly among those who were not vaccinated (OR 1.16, $95 \% \mathrm{Cl} 0.89$ to 1.51 ), among people vaccinated in the current season (OR $1.12,95 \% \mathrm{Cl} 0.91$ to 1.38 ) or among people vaccinated in previous seasons only (OR 1.05, 95\% $\mathrm{Cl} 0.71$ to 1.55 ). The estimates we derived from subanalyses involving outpatients and inpatients were similar between patients with or without asthma who were not vaccinated ( $p=0.1$ for interaction), vaccinated in the current season ( $p=0.4$ for interaction) or vaccinated in previous seasons only ( $p=0.9$ for interaction) (Table 5 and Appendix 1, Supplementary Table A5).

\section{Interpretation}

We evaluated the average effect over several seasons of influenza vaccination in preventing laboratory-confirmed influenza in people with asthma and compared this effect between outpatients and inpatients. Our results showed that current-season influenza vaccination had a moderate effect in preventing influenza. People vaccinated in previous seasons but not the current one retained a substantial protective effect. We found that current-season vaccination showed similar effects on preventing primary health care consultations and hospital admissions, and 


\begin{tabular}{|c|c|c|c|c|}
\hline Influenza vaccination status & $\begin{array}{l}\text { No. (\%) of patients } \\
\text { with confirmed } \\
\text { influenza } \\
n=421\end{array}$ & $\begin{array}{c}\text { No. }(\%) \text { of influenza- } \\
\text { negative patients } \\
n=611\end{array}$ & $\begin{array}{c}\text { Crude OR } \\
(95 \% \mathrm{CI})\end{array}$ & Adjusted OR $(95 \% \mathrm{CI})^{\star}$ \\
\hline Never vaccinated & 189 (44.9) & $156(25.5)$ & Ref. & Ref. \\
\hline Vaccination in previous seasons only & $53(12.6)$ & $102(16.7)$ & $0.43(0.29$ to 0.64$)$ & $0.63(0.40$ to 0.99$)$ \\
\hline 1 or 2 previous seasons & $29(6.9)$ & $54(8.8)$ & $0.44(0.27$ to 0.73$)$ & $0.62(0.36$ to 1.07$)$ \\
\hline 3-5 previous seasons & $24(5.7)$ & $48(7.9)$ & $0.41(0.24$ to 0.70$)$ & $0.66(0.36$ to 1.20$)$ \\
\hline Vaccination in current season & $179(42.5)$ & $353(57.8)$ & $0.42(0.32$ to 0.55$)$ & $0.57(0.40$ to 0.80$) \dagger$ \\
\hline Current season only & $10(2.4)$ & $25(4.1)$ & $0.33(0.15$ to 0.71$)$ & $0.30(0.13$ to 0.69$)$ \\
\hline Current and previous seasons & $169(4.1)$ & $328(53.7)$ & $0.43(0.32$ to 0.56$)$ & $0.61(0.43$ to 0.87$) \dagger$ \\
\hline 1 or 2 previous seasons & $20(4.8)$ & $46(7.5)$ & $0.36(0.20$ to 0.63$)$ & $0.51(0.27$ to 0.94$) \ddagger$ \\
\hline 3-5 previous seasons & $149(35.4)$ & $282(46.2)$ & $0.44(0.33$ to 0.58$)$ & $0.64(0.44$ to 0.92$) \ddagger$ \\
\hline \multicolumn{5}{|c|}{ 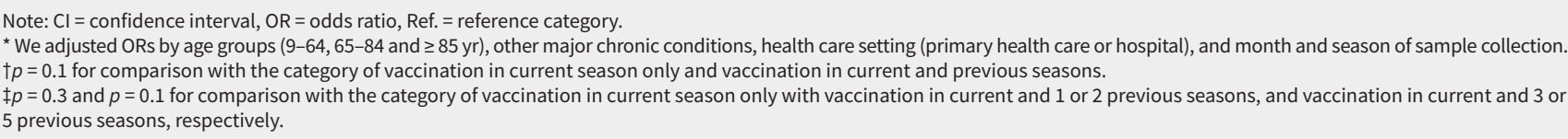 } \\
\hline
\end{tabular}

No. $(\%)$ of
patients with
confirmed
influenza

$\begin{array}{cc}\begin{array}{c}\text { No. }(\%) \text { of } \\ \text { influenza- } \\ \text { negative }\end{array} & \begin{array}{c}\text { Crude } \\ \text { vaccination } \\ \text { patfect, }\end{array} \\ \text { patients } & \%(95 \% \mathrm{Cl})\end{array}$

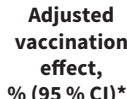

$\%(95 \% \mathrm{Cl})^{\star}$

\begin{tabular}{|c|c|c|c|}
\hline \multicolumn{4}{|l|}{ All patients } \\
\hline Current-season vaccination & $179(42.5)$ & $353(57.8)$ & 58 (45 to 68$)$ \\
\hline Vaccination in previous seasons only & $53(12.6)$ & $102(16.7)$ & 57 (34 to 71$)$ \\
\hline Never vaccinated & $189(44.9)$ & $156(25.5)$ & Ref. \\
\hline \multicolumn{4}{|l|}{ Primary health care patients } \\
\hline Current-season vaccination & $43(24.4)$ & $44(38.3)$ & 49 (15 to 70$)$ \\
\hline Vaccination in previous seasons only & $13(7.4)$ & $9(7.8)$ & 25 ( -85 to 70$)$ \\
\hline Never vaccinated & $120(68.2)$ & $62(53.9)$ & Ref. \\
\hline \multicolumn{4}{|l|}{ Hospital patients } \\
\hline Current-season vaccination & $136(55.5)$ & $309(62.3)$ & 41 (5 to 64$)$ \\
\hline Vaccination in previous seasons only & $40(16.3)$ & $93(18.8)$ & 40 (13 to 59$)$ \\
\hline Never vaccinated & $69(28.2)$ & $94(18.9)$ & Ref. \\
\hline \multicolumn{4}{|c|}{ Patients with other major chronic conditions } \\
\hline Current-season vaccination & $118(57.8)$ & $270(65.9)$ & 55 (26 to 73 ) \\
\hline Vaccination in previous seasons only & $26(12.8)$ & $75(18.3)$ & $62(27$ to 80$)$ \\
\hline Never vaccinated & $60(29.4)$ & $65(15.8)$ & Ref. \\
\hline
\end{tabular}
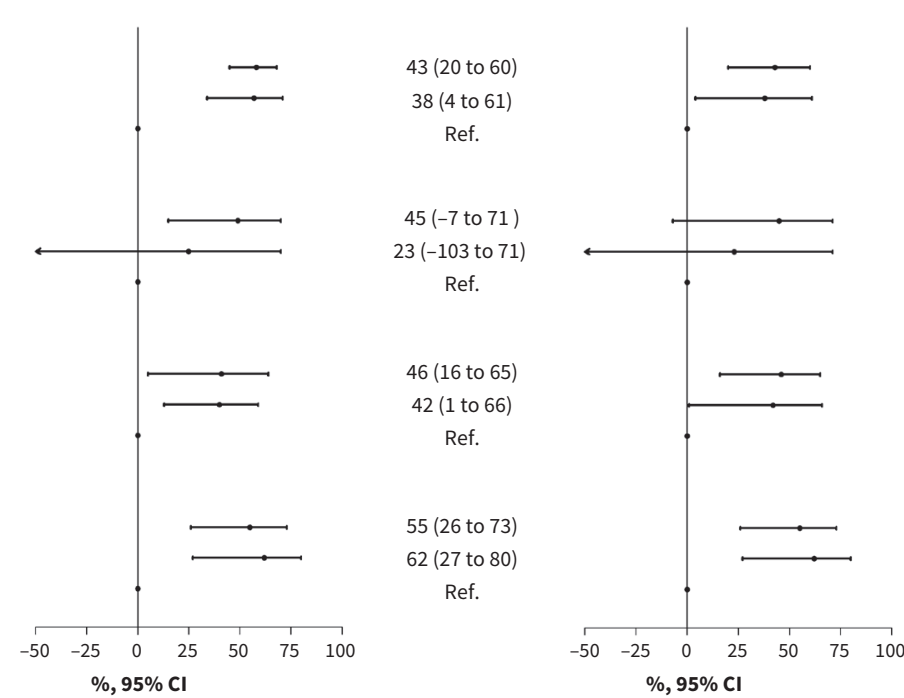

Figure 2: Effect of influenza vaccination in the current and 5 previous seasons in preventing influenza among patients with asthma. Effect of influenza vaccination was estimated as ( 1 - adjusted odds ratio $) \times 100$. Note: $\mathrm{Cl}=$ confidence interval, current-season vaccination $=$ vaccinated in the current season regardless of previous doses. *Vaccination effect adjusted by age groups (9-64, 65-84 and $\geq 85 \mathrm{yr}$ ), other major chronic conditions, health care setting (primary health care or hospital), and month and season of sample collection. †Interaction between health care setting and current season vaccination $(p=1.0)$ and vaccination in previous seasons $(p=0.7)$. Interaction between major chronic condition and current season vaccination $(p=0.4)$ and vaccination in previous seasons $(p=0.09)$.

vaccination in previous seasons showed a moderate effect on preventing hospital admission. These results support the benefit of influenza vaccination for people with asthma, who have an increased risk of hospital admission and severe complications from influenza. ${ }^{2-5}$
Although influenza vaccination was offered free of charge to all people in our population cohort with high-risk conditions; nearly half of those with asthma who we included in our study had not been vaccinated. This shows the need for additional efforts to increase vaccination coverage. 
Table 3: Effect of influenza vaccination in the current and 5 previous seasons in preventing influenza among patients with asthma, by age group and subtype

\begin{tabular}{|c|c|c|c|c|c|}
\hline Analysis subset & $\begin{array}{l}\text { No. }(\%) \text { of } \\
\text { patients with } \\
\text { confirmed } \\
\text { influenza }\end{array}$ & $\begin{array}{c}\text { No. }(\%) \text { of } \\
\text { influenza- } \\
\text { negative patients }\end{array}$ & $\begin{array}{l}\text { Crude OR } \\
(95 \% \mathrm{CI})\end{array}$ & $\begin{array}{l}\text { Adjusted OR } \\
(95 \% \mathrm{CI})^{\star}\end{array}$ & $\begin{array}{l}\text { Vaccination } \\
\text { effect, \% } \\
(95 \% \mathrm{CI})\end{array}$ \\
\hline \multicolumn{6}{|l|}{ Aged 9-64 yr } \\
\hline Total & $240(100)$ & $239(100)$ & & & \\
\hline Current-season vaccination & $52(21.7)$ & $92(38.4)$ & $0.40(0.27$ to 0.61$)$ & $0.45(0.28$ to 0.72$)$ ฯ & 55 (38 to 72 ) \\
\hline Vaccination in previous seasons only & $25(10.4)$ & $31(55.4)$ & 0.57 (0.32 to 1.02$)$ & 0.69 (0.36 to 1.32$)$ ฯ & $31(-32$ to 64$)$ \\
\hline Never vaccinated & $163(67.9)$ & $116(41.6)$ & Ref. & Ref. & Ref. \\
\hline \multicolumn{6}{|l|}{ Aged $\geq 65 \mathrm{yr}$} \\
\hline Total & $181(100)$ & $372(100)$ & & & \\
\hline Current-season vaccination & $127(70.2)$ & $261(70.2)$ & 0.75 (0.44 to 1.28$)$ & 0.67 (0.37 to 1.21$)$ ฯ & 33 ( -21 to 63$)$ \\
\hline Vaccination in previous seasons only & $28(15.5)$ & $71(18.1)$ & 0.61 (0.31 to 1.17$)$ & 0.61 (0.30 to 1.25$)$ ฯ & $39(-25$ to 70$)$ \\
\hline Never vaccinated & $26(14.4)$ & $40(10.8)$ & Ref. & Ref. & Ref. \\
\hline \multicolumn{6}{|l|}{ A/H1N1 subtype ${ }^{\dagger}$} \\
\hline Total & $155(100)$ & $517(100)$ & & & \\
\hline Current-season vaccination & $54(34.8)$ & $305(59.0)$ & 0.28 (0.19 to 0.42$)$ & $0.48(0.28$ to 0.80$)$ & 52 (20 to 72 ) \\
\hline Vaccination in previous seasons only & $17(11.0)$ & $79(15.3)$ & 0.34 (0.19 to 0.62$)$ & 0.65 (0.32 to 1.33$)$ & $35(-33$ to 68$)$ \\
\hline Never vaccinated & $84(54.2)$ & $133(25.7)$ & Ref. & Ref. & Ref. \\
\hline \multicolumn{6}{|l|}{ A/H3N2 subtype } \\
\hline Total & $147(100)$ & $464(100)$ & & & \\
\hline Current-season vaccination & $74(50.3)$ & $263(56.7)$ & 0.65 (0.43 to 0.98$)$ & 0.73 (0.43 to 1.22 ) & $27(-22$ to 57$)$ \\
\hline Vaccination in previous seasons only & $21(14.3)$ & $81(17.5)$ & 0.60 (0.34 to 1.07$)$ & 0.65 (0.34 to 1.25$)$ & $35(-25$ to 66$)$ \\
\hline Never vaccinated & $52(35.4)$ & $120(25.9)$ & Ref. & Ref. & Ref. \\
\hline \multicolumn{6}{|l|}{ B type§ } \\
\hline Total & $111(100)$ & $364(100)$ & & & \\
\hline Current-season vaccination & $47(42.3)$ & $215(59.1)$ & 0.44 (0.28 to 0.70$)$ & $0.49(0.26$ to 0.91$)$ & 51 (9 to 74$)$ \\
\hline Vaccination in previous seasons only & $14(12.6)$ & $49(13.5)$ & 0.57 (0.29 to 1.13$)$ & $0.66(0.29$ to 1.49$)$ & $34(-49$ to 71$)$ \\
\hline Never vaccinated & $50(45.1)$ & $100(27.5)$ & Ref. & Ref. & Ref. \\
\hline \multicolumn{6}{|c|}{$\begin{array}{l}\text { Note: } \mathrm{Cl}=\text { confidence interval, } \mathrm{OR}=\text { odds ratio, Ref. }=\text { reference category. Current-season vaccination = vaccinated in the current season regardless of previous doses. We estimated the } \\
\text { effect of influenza vaccination as }(1-\text { adjusted } \mathrm{OR}) \times 100 \text {. } \\
\text { *We adjusted } \mathrm{ORs} \text { by age groups }(9-64,65-84 \text { and } \geq 85 \text { yr), other major chronic conditions, health care setting (primary health care or hospital), and month and season of sample collection. } \\
\text { tPooled A/H1N1 analysis included } 2015 / 16,2017 / 18,2018 / 19 \text { and } 2019 / 20 \text { seasons. } \\
\text { tPooled } A / H 3 N 2 \text { analysis included } 2015 / 16,2016 / 17,2017 / 18 \text { and } 2018 / 19 \text { seasons. } \\
\text { \$Pooled B analysis included } 2015 / 16,2017 / 18 \text { and } 2019 / 20 \text { seasons. } \\
\text { IThere were no significant interactions between age group and current season vaccination }(p=0.3) \text { or vaccination in previous seasons }(p=0.9) \text {. }\end{array}$} \\
\hline
\end{tabular}

Table 4: Comparison of influenza vaccination status of inpatients and outpatients with asthma and confirmed influenza

\begin{tabular}{|c|c|c|c|c|}
\hline Influenza vaccination status & $\begin{array}{c}\text { No. }(\%) \text { of inpatients } \\
\text { with confirmed } \\
\text { influenza } \\
n=245\end{array}$ & $\begin{array}{l}\text { No. }(\%) \text { of outpatients } \\
\text { with confirmed } \\
\text { influenza } \\
n=176\end{array}$ & $\begin{array}{l}\text { Crude OR } \\
(95 \% \mathrm{CI})\end{array}$ & $\begin{array}{c}\text { Adjusted OR } \\
(95 \% \mathrm{CI})^{*}\end{array}$ \\
\hline Current-season vaccination & $136(55.5)$ & $43(24.4)$ & 5.50 (3.50 to 8.69$)$ & 1.05 (0.51 to 2.18 ) \\
\hline Vaccination in previous seasons only & $40(16.3)$ & $13(7.4)$ & 5.35 (2.68 to 10.69$)$ & 2.11 (0.88 to 5.07$)$ \\
\hline Never vaccinated & $69(28.2)$ & $120(68.2)$ & Ref. & Ref. \\
\hline
\end{tabular}


Table 5: Odds ratios for influenza in patients with asthma compared with the target population for influenza vaccination without asthma who had similar influenza vaccination status in the current and 5 previous seasons*

\begin{tabular}{|c|c|c|c|c|}
\hline Analysis subset & $\begin{array}{l}\text { No. }(\%) \text { of } \\
\text { patients with } \\
\text { confirmed } \\
\text { influenza }\end{array}$ & $\begin{array}{c}\text { No. }(\%) \text { of } \\
\text { influenza- } \\
\text { negative } \\
\text { patients }\end{array}$ & $\begin{array}{l}\text { Crude OR } \\
(95 \% \mathrm{CI})\end{array}$ & $\begin{array}{l}\text { Adjusted OR } \\
(95 \% \mathrm{CI}) \dagger\end{array}$ \\
\hline All patients & $2468(100)$ & $4444(100)$ & & \\
\hline $\begin{array}{l}\text { Patients with asthma who were vaccinated in the current season } \neq \\
\text { Target population without asthma who were vaccinated in the current season } \neq\end{array}$ & $\begin{array}{c}179(7.3) \\
983(39.8)\end{array}$ & $\begin{array}{c}353(7.9) \\
2342(52.7)\end{array}$ & $\begin{array}{l}1.21 \text { (0.99 to } 1.47) \\
\quad \text { Ref. }\end{array}$ & $\begin{array}{l}1.12 \text { (0.91 to } 1.38) \\
\text { Ref. }\end{array}$ \\
\hline $\begin{array}{l}\text { Patients with asthma who were vaccinated in previous seasons only } \\
\text { Target population without asthma who were vaccinated in previous seasons only }\end{array}$ & $\begin{array}{c}53(2.1) \\
236(9.6)\end{array}$ & $\begin{array}{l}102(2.3) \\
499(11.2)\end{array}$ & $\begin{array}{l}1.10 \text { ( } 0.76 \text { to } 1.59) \\
\text { Ref. }\end{array}$ & $\begin{array}{l}1.05 \text { (0.71 to } 1.55) \\
\text { Ref. }\end{array}$ \\
\hline $\begin{array}{l}\text { Unvaccinated patients with asthma } \\
\text { Unvaccinated target population without asthma }\end{array}$ & $\begin{array}{c}189(7.7) \\
828(33.5)\end{array}$ & $\begin{array}{c}156(3.5) \\
992(22.3)\end{array}$ & $\begin{array}{l}1.45 \text { (1.15 to } 1.83) \\
\text { Ref. }\end{array}$ & $\begin{array}{l}1.16 \text { (0.89 to } 1.51) \\
\text { Ref. }\end{array}$ \\
\hline Primary health care patients & $749(100)$ & $481(100)$ & & \\
\hline $\begin{array}{l}\text { Patients with asthma who were vaccinated in the current season } \ddagger \\
\text { Target population without asthma who were vaccinated in the current season } \neq\end{array}$ & $\begin{array}{c}43(5.7) \\
179(23.9)\end{array}$ & $\begin{array}{c}44(9.3) \\
164(34.8)\end{array}$ & $\begin{array}{l}0.90 \text { (0.56 to } 1.43) \\
\quad \text { Ref. }\end{array}$ & $\begin{array}{l}0.84(0.50 \text { to } 1.42) \S \\
\text { Ref. }\end{array}$ \\
\hline $\begin{array}{l}\text { Patients with asthma who were vaccinated in previous seasons only } \\
\text { Target population without asthma who were vaccinated in previous seasons only }\end{array}$ & $\begin{array}{l}13(1.7) \\
38(5.1)\end{array}$ & $\begin{array}{c}9(1.9) \\
30(6.4)\end{array}$ & $\begin{array}{l}1.14 \text { (0.43 to } 3.03) \\
\quad \text { Ref. }\end{array}$ & $\begin{array}{l}1.09 \text { (0.39 to } 3.05) \S \\
\text { Ref. }\end{array}$ \\
\hline $\begin{array}{l}\text { Unvaccinated patients with asthma } \\
\text { Unvaccinated target population without asthma }\end{array}$ & $\begin{array}{l}120(16.0) \\
356(47.5)\end{array}$ & $\begin{array}{c}62(13.2) \\
172(36.5)\end{array}$ & $\begin{array}{l}0.94 \text { (0.66 to } 1.34) \\
\text { Ref. }\end{array}$ & $\begin{array}{l}0.85 \text { (0.57 to } 1.29) \S \\
\text { Ref. }\end{array}$ \\
\hline Hospital patients & $1719(100)$ & $3963(100)$ & & \\
\hline $\begin{array}{l}\text { Patients with asthma who were vaccinated in the current season } \ddagger \\
\text { Target population without asthma who were vaccinated in the current season } \neq\end{array}$ & $\begin{array}{c}136(7.9) \\
804(46.8)\end{array}$ & $\begin{array}{c}309(7.8) \\
2178(55.0)\end{array}$ & $\begin{array}{l}1.19 \text { (0.96 to } 1.48) \\
\text { Ref. }\end{array}$ & $\begin{array}{l}1.18 \text { (0.94 to } 1.48) \S \\
\text { Ref. }\end{array}$ \\
\hline $\begin{array}{l}\text { Patients with asthma who were vaccinated in previous seasons only } \\
\text { Target population without asthma who were vaccinated in previous seasons only }\end{array}$ & $\begin{array}{c}40(2.3) \\
198(11.5)\end{array}$ & $\begin{array}{c}93(2.3) \\
469(11.8)\end{array}$ & $\begin{array}{l}1.02 \text { ( } 0.68 \text { to } 1.53) \\
\text { Ref. }\end{array}$ & $\begin{array}{l}1.05(0.69 \text { to } 1.60) \S \\
\text { Ref. }\end{array}$ \\
\hline $\begin{array}{l}\text { Unvaccinated patients with asthma } \\
\text { Unvaccinated target population without asthma }\end{array}$ & $\begin{array}{c}69(4.0) \\
472(27.5)\end{array}$ & $\begin{array}{c}94(2.4) \\
820(20.7)\end{array}$ & $\begin{array}{l}1.28 \text { (0.92 to } 1.78) \\
\quad \text { Ref. }\end{array}$ & $\begin{array}{l}1.37(0.96 \text { to } 1.95) \S \\
\text { Ref. }\end{array}$ \\
\hline \multicolumn{5}{|c|}{$\begin{array}{l}\text { Note: } \mathrm{Cl}=\text { confidence interval, } \mathrm{OR}=\text { odds ratio, Ref. = reference category. } \\
\text { *Target population for influenza vaccination included people aged } 60 \text { years and older or with major chronic conditions. } \\
\text { tWe adjusted ORs for age groups }(9-64,65-84 \text { and } \geq 85 \text { yr), other major chronic conditions, health care setting (primary health care or hospital), and month and season of sample collection. } \\
\text { tVaccinated in the current season regardless of previous doses. } \\
\S \text { There were no significant interactions between health care setting and asthma for patients who were unvaccinated }(p=0.1) \text {, vaccinated in the current season ( } p=0.4 \text { ) or vaccinated in } \\
\text { previous seasons }(p=0.9) \text {. }\end{array}$} \\
\hline
\end{tabular}

Our estimation of the effect of influenza vaccination among people with asthma is consistent with the pooled estimate of $45 \%$ reported in a 2017 systematic review. ${ }^{16} \mathrm{~A}$ similar result was reported in a case-control study involving people with asthma in Scotland over 6 influenza seasons. ${ }^{13}$ These studies evaluated influenza vaccine effectiveness for preventing primary health care visits or hospital admissions for influenza among people with asthma, but none of them evaluated and compared results from both settings, considered the vaccination history or included a comparison with people without asthma. ${ }^{13,16}$

Patients with asthma may accumulate several doses of vaccines over the years. Although previous-season vaccination may maintain a substantial protective effect in future seasons, ${ }^{27-30}$ we are unaware of any studies that evaluated the effect of influenza vaccination and considered the vaccination history of patients with asthma. We found a residual protective effect if the patient had been vaccinated in previous seasons. A 2015 immunogenicity study showed that the level of antibodies peaks a few weeks after vaccination and then progressively declines, although it may persist for years, in particular when vaccine components remain unchanged or the antigenic distance is small. ${ }^{31}$ In a previous study, we found that, on average, the annual drift of influenza viruses was not sufficient to completely nullify the protective effect of the influenza vaccines received in previous seasons. ${ }^{29}$ Not receiving an annual vaccination has been related to neglecting to seek vaccination, a recent diagnosis of a major condition or a recent hospital admission. ${ }^{32}$ In these instances, the residual effect of previous vaccinations may be essential for preventing influenza infections in patients with asthma.

We observed a similar effect in preventing influenza in our target population for influenza vaccination of patients with and without asthma. A study that used data from the U.S. Influenza Vaccine Effectiveness Network did not find differences in vaccination effect in preventing outpatient consultations among people with different high-risk medical conditions, including asthma. ${ }^{33}$ Thus, estimates for annual influenza vaccine effectiveness that are obtained for overall risk populations may be valid for people with asthma.

Our study has several strengths. The test-negative design is accepted as the reference method to be used for studies of influenza vaccine effectiveness. ${ }^{17-19}$ We included only patients with laboratory-confirmed influenza and controls who had influenza 
excluded by laboratory testing. Both groups had similar symptoms and were recruited from the same population and influenza seasons, received the same vaccine and were exposed to the same circulating viruses, which ensures comparability between cases and controls, reduces selection bias and helps to prevent unmeasured confounding. ${ }^{17-19,34,35}$ We obtained vaccination history from the regional vaccination registry, ${ }^{9}$ and the study was limited to the population with stable residence in the region to avoid biases due to incomplete information.

\section{Limitations}

We obtained asthma diagnosis data from primary health care electronic records; therefore, some misclassification is possible. Information on asthma severity was not available. This study was carried out in a single region in Spain where influenza vaccination was recommended for people older than 60 years or for those with risk factors, and only inactivated trivalent vaccine was administered. Consequently, care must be taken when generalizing these results to other countries with different vaccine indications or coverage, or where other types of vaccines are used. We did not include cases of influenza that were not medically attended. As this is a pooled analysis conducted over 5 influenza seasons, the results should be understood as an average. Observational studies may be affected by confounding; although we adjusted analyses for the main potential confounding variables, some residual confounding may have occurred. ${ }^{35}$ Nevertheless, the test-negative design achieved a high comparability between cases and controls because we included both in a blinded manner. Caution should be paid in the interpretation of results for a single season, patients who were seen at primary health care centres and the interaction between variables, because the statistical power was reduced.

\section{Conclusion}

We found that on average, current-season influenza vaccination was moderately effective in preventing influenza in people with asthma, with no difference identified in preventing influenza requiring inpatient versus outpatient care. Vaccination in previous seasons maintained an appreciable protective effect that was important to prevent hospital admissions. As the effect of influenza vaccination in people with asthma was similar to that in people with other chronic conditions, we believe that the estimates obtained for all patients with chronic conditions may be valid for this risk group. Our results reinforce the recommendation of annual influenza vaccination and highlight the need for additional efforts to increase coverage in people with asthma.

\section{References}

1. Influenza (seasonal). Geneva: World Health Organization; 2018. Available: https://www.who.int/en/news-room/fact-sheets/detail/influenza-(seasonal) (accessed 2020 Nov. 18).

2. Cohen L, Castro M. The role of viral respiratory infections in the pathogenesis and exacerbation of asthma. Semin Respir Infect 2003;18:3-8.

3. Teichtahl H, Buckmaster N, Pertnikovs E. The incidence of respiratory tract infection in adults requiring hospitalization for asthma. Chest 1997;112:591-6.

4. likura M, Hojo M, Koketsu R, et al. The importance of bacterial and viral infections associated with adult asthma exacerbations in clinical practice. PLoS One 2015;10:e0123584.
5. Schwarze J, Openshaw P, Jha A, et al. Influenza burden, prevention, and treatment in asthma - a scoping review by the EAACI influenza in asthma task force. Allergy 2018;73:1151-81.

6. Risk groups for severe influenza. Solna (Sweden): European Centre for Disease Prevention and Control. Available: https://ecdc.europa.eu/en/seasonal-influenza /prevention-and-control/vaccines/risk-groups (accessed 2020 Nov. 18)

7. Paules C, Subbarao K. Influenza. Lancet 2017;390:697-708.

8. Cates CJ, Rowe BH. Vaccines for preventing influenza in people with asthma. Cochrane Database Syst Rev 2013;2013(2):CD000364.

9. Aguilar I, Reyes M, Martínez-Baz I, et al. Use of the vaccination register to evaluate influenza vaccine coverage in seniors in the 2010/11 influenza season, Navarre, Spain. Euro Surveill 2012;17:20154.

10. Santos-Sancho JM, López-de Andrés A, Jimenez-Trujillo I, et al. Adherence and factors associated with influenza vaccination among subjects with asthma in Spain. Infection 2013;41:465-71.

11. Juhn YJ. Risks for infection in patients with asthma (or other atopic conditions): is asthma more than a chronic airway disease? J Allergy Clin Immunol 2014;134: 247-57, quiz 58-9.

12. Ritchie Al, Farne HA, Singanayagam A, et al. Pathogenesis of viral infection in exacerbations of airway disease. Ann Am Thorac Soc 2015;12(Suppl 2):S115-32.

13. Vasileiou E, Sheikh A, Butler CC, et al. Seasonal influenza vaccine effectiveness in people with asthma: a national test-negative design case-control study. Clin Infect Dis 2020;71:e94-e104.

14. Domínguez A, Godoy P, Torner N. The effectiveness of influenza vaccination in different groups. Expert Rev Vaccines 2016;15:751-64.

15. Morales-Suárez-Varela M, Llopis-González A, Vergara-Hernández C, et al. Asthma in older people hospitalized with influenza in Spain: a case-control study. Allergy Asthma Proc 2017;38:277-85.

16. Vasileiou E, Sheikh A, Butler C, et al. Effectiveness of influenza vaccines in asthma: a systematic review and meta-analysis. Clin Infect Dis 2017;65:1388-95.

17. Broome CV, Facklam RR, Fraser DW. Pneumococcal disease after pneumococcal vaccination: an alternative method to estimate the efficacy of pneumococcal vaccine. N Engl J Med 1980;303:549-52.

18. Evaluation of influenza vaccine effectiveness: a guide to the design and interpre tation of observational studies. Geneva: World Health Organization; 2017. Available: https://apps.who.int/iris/bitstream/handle/10665/255203/9789241512121 -eng.pdf?sequence=1 (accessed 2020 Nov. 18).

19. Foppa IM, Ferdinands JM, Chaves SS, et al. The case test-negative design for studies of the effectiveness of influenza vaccine in inpatient settings. Int J Epidemiol 2016;45:2052-9.

20. Castilla J, Navascués A, Fernández-Alonso M, et al. Effects of previous episodes of influenza and vaccination in preventing laboratory confirmed influenza in Navarra, Spain, 2013/14 season. Euro Surveill 2016;20:30243.

21. Castilla J, Navascués A, Casado I, et al. Combined effectiveness of prior and current season influenza vaccination in northern Spain: 2016/17 mid-season analysis. Euro Surveill 2017;22:30465.

22. Castilla J, Navascués A, Casado I, et al. Interim effectiveness of trivalent influ enza vaccine in a season dominated by lineage mismatched influenza B, northern Spain, 2017/18. Euro Surveill 2018;23:18-00057.

23. European Commission. Commission Decision of 28 April 2008 amending Decision 2002/253/EC laying down case definitions for reporting communicable diseases to the Community network under Decision No. 2119/98/EC of the European Parliament and of the Council. Luxembourg: OJEU 18.6.2008:L 159/46. Available: http://eur-lex.europa.eu/LexUriServ/LexUriServ.do?uri $=0 J: L: 2008: 159: 0046: 0090: E N: P D F$ (accessed 2020 Nov. 18).

24. World Organization of National Colleges Academies. International classification of primary care. 2nd ed. Oxford: Oxford University Press; 1998.

25. Castilla J, Godoy P, Domínguez A, et al. Influenza vaccine effectiveness in preventing outpatient, inpatient, and severe cases of laboratory-confirmed influenza. Clin Infect Dis 2013;57:167-75.

26. Martínez-Baz I, Navascués A, Portillo ME, et al. Effect of influenza vaccination in preventing laboratory-confirmed influenza hospitalization in patients with diabetes mellitus. Clin Infect Dis 2020 May 15 [Epub ahead of print];ciaa564. doi: 10.1093/cid/ciaa564. 
27. Ramsay LC, Buchan SA, Stirling RG, et al. The impact of repeated vaccination on influenza vaccine effectiveness: a systematic review and meta-analysis. BMC Med 2019;17:9.

28. Belongia EA, Skowronski DM, McLean HQ, et al. Repeated annual influenza vaccination and vaccine effectiveness: review of evidence. Expert Rev Vaccines 2017;16:1-14.

29. Martínez-Baz I, Navascués A, Casado I, et al. Remaining effect of influenza vaccines received in prior seasons. J Infect Dis 2019;220:1136-40.

30. McLean HQ, Thompson MG, Sundaram ME, et al. Impact of repeated vaccination on vaccine effectiveness against influenza $A(H 3 N 2)$ and $B$ during 8 seasons. Clin Infect Dis 2014;59:1375-85.

31. Petrie JG, Ohmit SE, Johnson E, et al. Persistence of antibodies to influenza hemagglutinin and neuraminidase following one or two years of influenza vaccination. J Infect Dis 2015;212:1914-22.
32. Martínez-Baz I, Aguilar I, Morán J, et al. Factors associated with continued adherence to influenza vaccination in the elderly. Prev Med 2012;55:246-50.

33. Shang M, Chung JR, Jackson ML, et al. Influenza vaccine effectiveness among patients with high-risk medical conditions in the United States, 2012-2016. Vaccine 2018;36:8047-53.

34. Belongia EA, Simpson MD, King JP, et al. Variable influenza vaccine effectiveness by subtype: a systematic review and meta-analysis of test-negative design studies. Lancet Infect Dis 2016;16:942-51.

35. Groenwold RH, Hoes AW, Nichol KL, et al. Quantifying the potential role of unmeasured confounders: the example of influenza vaccination. Int J Epidemiol 2008;37:1422-9.

\section{Competing interests: None declared.}

This article has been peer reviewed.

Affiliations: Instituto de Salud Pública de Navarra - IdiSNA (Martínez-Baz, Casado, Guevara, Gómez-Ibáñez, Burgui, Castilla); Servicio de Microbiología Clínica, Complejo Hospitalario de Navarra - IdiSNA (Navascués, Portillo, Ezpeleta), Pamplona, Spain; CIBER Epidemiología y Salud Pública, (Martínez-Baz, Casado, Guevara, Burgui, Castilla) Madrid, Spain.

Contributors: Iván Martínez-Baz conducted the statistical analyses and had full access to the study data. Iván Martínez-Baz and Jesús Castilla wrote the initial draft of the manuscript. All of the authors participated in the design, implementation and interpretation of the study; critically revised the manuscript; gave final approval of the version to be published; and agreed to act as guarantors of the work.

Content licence: This is an Open Access article distributed in accordance with the terms of the Creative Commons Attribution (CC BY-NC-ND 4.0) licence, which permits use, distribution and reproduction in any medium, provided that the original publication is properly cited, the use is noncommercial (i.e., research or educational use), and no modifications or adaptations are made. See: https://creativecommons.org/licenses/ by-nc-nd/4.0/

Funding: This study was funded by the European Centre for Disease Prevention and Control (I-MOVE Network), the Horizon 2020 program of the European Commission (I-MOVE-plus, agreement 634446), EpiConcept and the Carlos III Institute of Health with the European Regional Development Fund (PI17/00868, PI12/00087, CM19/00154 and INT19/00028). The funders had no role in study design, data collection and analysis, decision to publish or preparation of the manuscript.

Data sharing: If approved by the study institutions through datasharing agreements, de-identified data can be made available for use by other researchers.

Accepted: May 13, 2021

Correspondence to: Jesús Castilla, jcastilc@navarra.es 